\title{
Influence of national culture on the adoption of integrated medical curricula
}

\author{
Mariëlle Jippes • Gerard D. Majoor
}

Received: 22 November 2009/Accepted: 12 May 2010/Published online: 25 July 2010

(C) The Author(s) 2010. This article is published with open access at Springerlink.com

\begin{abstract}
Integrated curricula have been implemented in medical schools all over the world. However, among countries different relative numbers of schools with integrated curricula are found. This study aims to explore the possible correlation between the percentage of medical schools with integrated curricula in a country and that country's cultural characteristics. Curricula were defined as not integrated if in the first 2 years of the program at least two out of the three monodisciplinary courses Anatomy, Physiology and Biochemistry were identified. Culture was defined using Hofstede's dimensions Power distance, Uncertainty avoidance, Masculinity/Femininity, and Individualism/Collectivism. Consequently, this study had to be restricted to the 63 countries included in Hofstede's studies which harbored 1,195 medical schools. From each country we randomly sampled a maximum of 15 schools yielding 484 schools to be investigated. In total $91 \%$ (446) of the curricula were found. Correlation of percent integrated curricula and each dimension of culture was determined by calculating Spearman's Rho. A high score on the Power distance index and a high score on the Uncertainty avoidance index correlated with a low percent integrated curricula; a high score on the Individualism index correlated with a high percent integrated curricula. The percentage integrated curricula in a country did not correlate with its score on the Masculinity index. National culture is associated with the propensity of medical schools to adopt integrated medical curricula. Consequently, medical schools considering introduction of integrated and problem-based medical curricula should take into account dimensions of national culture which may hinder the innovation process.
\end{abstract}

Keywords National culture $\cdot$ Curriculum innovation · Integrated curricula

\footnotetext{
M. Jippes $(\bowtie)$

Department of Educational Development and Research FHML, Maastricht University, POB 616, 6200 MD Maastricht, The Netherlands e-mail: mjippes@hotmail.com
}

G. D. Majoor

Institute for Education, Faculty of Health, Medicine and Life Sciences, Maastricht University, Maastricht, The Netherlands 


\section{Introduction}

Globalization has confronted higher education with cross-cultural issues. For instance, currently students from developing countries may enroll in higher education in industrialized countries. Apart from adapting their daily lives to another culture, these students also may have to adapt to a pedagogical approach which may be different from that encountered in their secondary school education (Charlesworth 2008). One may also wonder whether new didactic approaches, like problem-based learning (PBL) developed in industrialized countries, can also be applied in different cultural settings (Gwee 2008). The current interest of universities in developed countries to incept satellite institutions in developing countries has added cross-cultural management of education to the issues pertaining to cross-cultural teaching and learning (Eldridge and Cranston 2009). In this study we aim to investigate the impact of national culture on the propensity of educational institutions to adopt educational innovations. We explored whether national culture is related with the relative number of medical schools in a country that adopted integrated medical curricula.

As of the middle of the previous century medical curricula based on monodisciplinary courses in basic and (pre-)clinical sciences have been challenged. Major disadvantages identified for this discipline-based curriculum model were (1) exclusion of contacts of students with patients in the pre-clinical phase; (2) the haphazard sequence of presentation of basic sciences courses frustrating integration in a knowledge-base relevant for clinical contexts; and (3) departmental autonomy over the courses yielding programs to educate mini-scientists (Papa and Harasym 1999). In response, innovative curricula were constructed built from educational units focusing on organ systems or clinical problem areas like pain or blood loss. For such 'integrated curricula' both integration of basic sciences ('horizontal integration') and of basic sciences with clinical sciences ('vertical integration') was advocated (Harden et al. 1984). Integrated curricula have been implemented by a growing number of medical schools all over the world, including schools based in industrialized and in developing countries. However, differences exist between countries with respect to the relative number of medical schools that adopted integrated curricula. Focusing on Europe a preponderance of schools with problem-based learning (PBL) curricula was observed in the North of Europe and few successful implementations of such curricula in the European Mediterranean countries. An impact of national culture on the successful implementation of PBL and integrated curricula was supposed (Jippes and Majoor 2008; Stevens 2009). In our 2008 study we demonstrated for 17 European countries a correlation between the relative number of medical schools with integrated curricula and two out of four dimensions of culture as defined by Hofstede (Jippes and Majoor 2008; Hofstede 2001). According to him, Power distance is 'the extent to which the less powerful members of institutions and organizations within a country expect and accept that power is distributed unequally'. A high score on the sliding scale of the Individualism/Collectivism index indicates Individualism and 'pertains to societies in which the ties between individuals are loose: everybody is expected to look after him/herself and his/her immediate family'. A low score on the Individualism/Collectivism index indicates Collectivism and 'pertains to societies in which people from birth onwards are integrated into strong, cohesive in-groups, which throughout people's lifetime continue to protect them in exchange for unquestioning loyalty'. A high score on the sliding scale of the Masculinity/ Femininity index indicates Masculinity and 'pertains to societies in which social gender roles are clearly distinct (i.e. men are supposed to be assertive, tough, and focused on material success, whereas women are supposed to be more modest, tender, and concerned 
with the quality of life)'. A low score on the Masculinity/Femininity index indicates Femininity and 'pertains to societies in which social gender roles overlap (i.e. both men and women are supposed to be modest, tender and concerned with the quality of life)'. Uncertainty avoidance is 'the extent to which the members of a culture feel threatened by uncertain or unknown situations. This feeling is, among others, expressed through nervous stress and in a need for predictability: a need for written and unwritten rules'. European countries scoring high on Hofstede's indexes for the dimensions 'Power distance' and/or 'Uncertainty avoidance' had relatively less medical schools with integrated curricula. No correlation was found with two other of Hofstede's dimensions of culture, i.e. 'Individualism/Collectivism' and 'Masculinity/Femininity'.

Based on a literature review in 2000 Bland et al. (2000) identified 13 factors contributing to successful curriculum change. Some of these factors were also emphasized in a book chapter published by Davis and White (2002). As indicated by the latter authors, studies like these may be biased towards North America and thus almost eliminate the possible impact of different national cultures. On the other hand, world-wide medical schools consider or attempt to introduce integrated and PBL curricula. Being aware of the potential impact of culture on the innovation process and trying to circumvent possible negative aspects may help to prevent frustration and waste of time and money. Therefore, this study aims to investigate at global scale whether a relation exists between the relative number of medical schools with integrated curricula in a country and that country's scores on Hofstede's indexes for four dimensions of culture. Based on our findings for Europe we hypothesized countries scoring high on Hofstede's indexes for the culture dimensions 'Power distance' and/or 'Uncertainty avoidance' to have relatively less medical schools with integrated medical curricula than countries scoring low on the indexes for these dimensions. No relation was presumed with the culture dimensions 'Individualism/Collectivism' and 'Masculinity/Femininity'.

\section{Methods}

To investigate the influence of national culture on the adoption of integrated medical curricula 'national culture' and 'integrated curricula' had to be defined and operationalized. A representative sample of medical schools from all over the world was needed that would allow for testing the above hypothesis.

\section{Definition of national culture}

In the 1970's Hofstede surveyed through questionnaires employees of IBM branches in 80 countries dispersed over the world to record their perception of organizational culture in the office. Criticism on Hofstede's derived construct of dimensions of culture includes the restricted population sample of IBM employees and his presumption that each country harbours one culture. Nevertheless, Hofstede's dimensions of culture are widely adopted and suited to perform our studies. Fourty individual countries were included in his initial studies (Hofstede 1980). Later another 10 countries and 3 clusters of countries were added: Arab World, seven countries; East-Africa, four countries; and West-Africa, three countries. Clusters of countries were created because countries therein did not meet Hofstede's inclusion criteria for individual countries (Hofstede 2001). From his data Hofstede extracted the four dimensions of culture quoted in the Introduction and a fifth one: Short/ Long term orientation. In principle for each country and each cluster of countries scores on 
semi-quantitative indexes for each dimension of culture were calculated. However, the dimension 'Short/long term orientation' could not be included in this study because only a limited number of countries were assessed on that dimension. Furthermore, Yugoslavia was deleted from Hofstede's selection of individual countries because the country does not exist anymore.

\section{Assessment of integrated and non-integrated curricula}

The first 2 years of the curricula of medical schools were assessed to differentiate between integrated and non-integrated curricula. The curriculum was scored as non-integrated if at least two of the common preclinical disciplines Anatomy, Physiology and Biochemistry were presented as individual courses (Aziz and Cullen 1994). If none or only one of these courses was found the curriculum was assumed to be integrated. Screening of curricula was performed independently by both authors. Disconcordant classifications of curricula (41 out of 461 cases) were re-examined and discussed to reach consensus.

\section{Sample of medical schools}

The design of this study dictated that only medical schools based in the 64 countries investigated by Hofstede (minus Yugoslavia) could be used to sample medical schools from. According to the World Directory of Medical Schools (WDMS) in 2003 these countries and clusters of countries harbored 1,184 medical schools (WHO 2003). In that directory Taiwan was not represented. For Taiwan 11 medical schools were sampled from the International Medical Education Directory (IMED) of the Foundation for Advancement of International Medical Education and Research (FAIMER 2008), yielding a total number of 1,195 medical schools. If the number of medical schools in an individual country did not exceed 15 all schools were included. From 19 countries with more than 15 medical schools (range 16-148) 15 schools were sampled at random representing at least $10 \%$ of the total number of schools in that country. Four countries assigned by Hofstede to the cluster EastAfrica (Ethiopia, Kenya, Tanzania and Zambia) contained eight medical schools which were all included. Seven countries included in the cluster 'Arab World' (Egypt, Iraq, Kuwait, Lebanon, Libya, Saudi-Arabia and the United Arab Emirates) harbored 40 medical schools from which a stratified random sample of 15 was drawn. The same procedure was applied to the 19 medical schools based in the three countries assigned to the cluster WestAfrica (Ghana, Nigeria and Sierra Leone). These sampling procedures yielded a final sample of 484 medical schools based in 63 countries representing all continents.

\section{Collection of information on curricula}

Websites of sampled medical schools were searched for specification of their curriculum of the first 2 years. Information on most European schools was collected from JuneAugust 2006 and on all other schools from June-October 2008. If a school's website could not be found, or if the website did not yield adequate information that medical school was contacted by e-mail. In case the request by e-mail elicited no response a fax was sent, if necessary followed by a surface mail. If all attempts to establish contact failed colleagues in the same country as the unresponsive school were asked for help to retrieve information. 
Websites and electronic files provided in languages not mastered by us were translated into English through the website 'www.translate.google.com'. The languages of Thailand and Indonesia were not supported by this site; for that purpose, respectively, " www.thai2english.com' and 'www.yyy.sederet.com/translate.php' were used. If translation programs did not yield adequate information bilingual colleagues were contacted to translate the essential information to English.

Statistical analysis

SPSS version 15 was used to calculate Spearman's Rho: correlation coefficients (CC) between the percent medical schools with an integrated curriculum in a country and that country's scores on the respective indexes of four of Hofstede's dimensions of culture. A correlation was considered significant if $P<0.05$ (2-tailed).

\section{Results}

Satisfactory information on the first 2 years of the curriculum could be collected from 466 of the 484 medical schools included in the sample (91\%). The curricula of nine medical schools in Iran could not be directly accessed. However, two colleagues in Iran independently assured us that medical schools in their country all had similar, non-integrated curricula.

In Venezuela information on only five out of the nine medical schools in that country was obtained and therefore this country was excluded from further analyses. Eventually a total of 461 medical curricula were included in the analysis. In 14 countries none of the medical schools examined had an integrated curriculum and in 6 countries all medical schools had integrated curricula. Overall 134 of the 461 medical curricula examined (29\%) were classified as integrated (Table 1).

Scatter plots for the variables 'percent integrated curricula in a country' and that country's 'score on the index' for each of the four dimensions of culture are shown in Fig. 1. Significant negative correlations were found between percent integrated curricula and a country's score on the Power distance index $(\mathrm{CC}=-0.352, P=0.01)$ and the Uncertainty avoidance index $(\mathrm{CC}=-0.658, P=0.000)$, and a significant positive correlation with the score on the Individualism index $(C C=0.387, P=0.005)$. No significant correlation was found between the percentage of integrated curricula in a country and that country's score on the Masculinity index.

\section{Discussion}

A significant correlation was found between the relative number of integrated medical curricula in a country and that country's scores on indexes for three dimensions of culture as defined by Hofstede (2001). In accord with our hypothesis, respectively, a high score on Power distance and a high score on Uncertainty avoidance correlated with a low percentage of integrated curricula in a country. At variance with our working hypothesis a high score of a country on the Individualism index was also found to correlate significant with a high percentage integrated curricula.

In our study focusing on Europe explanations for the correlation of strong Power distance and strong Uncertainty avoidance with a low percentage integrated curricula were 
Table 1 Percent integrated medical curricula in 49 countries and 3 clusters of countries and their scores on Hofstede's indexes for 4 dimensions of culture

\begin{tabular}{|c|c|c|c|c|c|c|c|}
\hline \multirow[t]{2}{*}{ Country } & \multicolumn{3}{|c|}{ Medical schools ${ }^{\mathrm{a}}$} & \multicolumn{4}{|c|}{ Dimensions of culture $^{\mathrm{b}}$} \\
\hline & Total & Included & $\begin{array}{l}\text { Integrated } \\
\text { curricula (\%) }\end{array}$ & PD score & IND score & MAS score & UA score \\
\hline Arab World & 40 & $14^{\mathrm{c}, \mathrm{d}}$ & 29 & 80 & 38 & 52 & 68 \\
\hline Argentina & 14 & $13^{\mathrm{d}}$ & 15 & 49 & 46 & 56 & 86 \\
\hline Australia & 11 & 11 & 100 & 36 & 90 & 61 & 51 \\
\hline Austria & 3 & 3 & 100 & 11 & 55 & 79 & 70 \\
\hline Belgium & 11 & $10^{\mathrm{e}}$ & 10 & 65 & 75 & 54 & 94 \\
\hline Brazil & 82 & $12^{\mathrm{c}, \mathrm{d}}$ & 17 & 69 & 38 & 49 & 76 \\
\hline Canada & 16 & $15^{\mathrm{c}}$ & 73 & 39 & 80 & 52 & 48 \\
\hline Chile & 7 & 7 & 43 & 63 & 23 & 28 & 86 \\
\hline Colombia & 28 & $12^{\mathrm{c}, \mathrm{d}}$ & 33 & 67 & 13 & 64 & 80 \\
\hline Costa Rica & 5 & 5 & 0 & 35 & 15 & 21 & 86 \\
\hline Denmark & 3 & 3 & 33 & 18 & 74 & 16 & 23 \\
\hline East Africa & 8 & 8 & 13 & 64 & 27 & 41 & 52 \\
\hline Ecuador & 10 & $9^{\mathrm{d}}$ & 11 & 78 & 8 & 63 & 67 \\
\hline El Salvador & 6 & 6 & 0 & 66 & 19 & 40 & 94 \\
\hline Finland & 5 & 5 & 60 & 33 & 63 & 26 & 59 \\
\hline France & 45 & $15^{\mathrm{c}}$ & 0 & 68 & 71 & 43 & 86 \\
\hline Germany & 39 & $15^{\mathrm{c}}$ & 33 & 35 & 67 & 66 & 65 \\
\hline Greece & 7 & 7 & 0 & 60 & 35 & 57 & 112 \\
\hline Guatemala & 2 & 2 & 0 & 95 & 6 & 37 & 101 \\
\hline Hong Kong & 2 & 2 & 100 & 68 & 25 & 57 & 29 \\
\hline India & 146 & $15^{\mathrm{c}}$ & 0 & 77 & 48 & 56 & 40 \\
\hline Indonesia & 32 & $14^{\mathrm{c}, \mathrm{d}}$ & 21 & 78 & 14 & 46 & 48 \\
\hline Iran & 46 & $15^{\mathrm{c}}$ & 0 & 58 & 41 & 43 & 59 \\
\hline Ireland & 5 & 5 & 40 & 28 & 70 & 68 & 35 \\
\hline Israel & 4 & 4 & 0 & 13 & 54 & 47 & 81 \\
\hline Italy & 31 & $15^{\mathrm{c}}$ & 0 & 50 & 76 & 70 & 75 \\
\hline Jamaica & 1 & 1 & 100 & 45 & 39 & 68 & 13 \\
\hline Japan & 80 & $15^{\mathrm{c}}$ & 13 & 54 & 46 & 95 & 92 \\
\hline Malaysia & 8 & $7^{\mathrm{d}}$ & 86 & 104 & 26 & 50 & 36 \\
\hline Mexico & 56 & $15^{\mathrm{c}}$ & 20 & 81 & 30 & 69 & 82 \\
\hline New Zealand & 2 & 2 & 100 & 22 & 79 & 58 & 49 \\
\hline Norway & 4 & 4 & 50 & 31 & 69 & 8 & 50 \\
\hline Pakistan & 25 & $14^{\mathrm{c}, \mathrm{d}}$ & 14 & 55 & 14 & 50 & 70 \\
\hline Panama & 3 & 3 & 0 & 95 & 11 & 44 & 86 \\
\hline Peru & 17 & $13^{\mathrm{c}, \mathrm{d}}$ & 8 & 64 & 16 & 42 & 87 \\
\hline Philippines & 30 & $11^{\mathrm{c}, \mathrm{d}}$ & 9 & 94 & 32 & 64 & 44 \\
\hline Portugal & 5 & $4^{\mathrm{d}}$ & 0 & 63 & 27 & 31 & 104 \\
\hline Singapore & 1 & 1 & 100 & 74 & 20 & 48 & 8 \\
\hline South Africa & 8 & 8 & 75 & 49 & 65 & 63 & 49 \\
\hline South Korea & 49 & $13^{\mathrm{c}, \mathrm{d}}$ & 8 & 60 & 18 & 39 & 85 \\
\hline
\end{tabular}


Table 1 continued

\begin{tabular}{|c|c|c|c|c|c|c|c|}
\hline \multirow[t]{2}{*}{ Country } & \multicolumn{3}{|c|}{ Medical schools ${ }^{\mathrm{a}}$} & \multicolumn{4}{|c|}{ Dimensions of culture $^{b}$} \\
\hline & Total & Included & $\begin{array}{l}\text { Integrated } \\
\text { curricula }(\%)\end{array}$ & PD score & IND score & MAS score & UA score \\
\hline Spain & 26 & $15^{\mathrm{c}}$ & 0 & 57 & 51 & 42 & 86 \\
\hline Sweden & 6 & 6 & 67 & 31 & 71 & 5 & 29 \\
\hline Switzerland & 5 & 5 & 60 & 34 & 68 & 70 & 58 \\
\hline Taiwan & 11 & $9^{d}$ & 11 & 58 & 17 & 45 & 69 \\
\hline Thailand & 12 & $10^{\mathrm{d}}$ & 40 & 64 & 20 & 34 & 64 \\
\hline The Netherlands & 8 & 8 & 88 & 38 & 80 & 14 & 53 \\
\hline Turkey & 33 & $14^{\mathrm{c}, \mathrm{d}}$ & 50 & 66 & 37 & 45 & 85 \\
\hline United States & 141 & $15^{\mathrm{c}}$ & 53 & 40 & 91 & 62 & 46 \\
\hline United Kingdom & 27 & $15^{\mathrm{c}}$ & 87 & 35 & 89 & 66 & 35 \\
\hline Uruguay & 1 & 1 & 0 & 61 & 36 & 38 & 100 \\
\hline Venezuela & 9 & $0^{\mathrm{f}}$ & & & & & \\
\hline West Africa & 19 & $10^{\mathrm{c}, \mathrm{d}}$ & 0 & 77 & 20 & 46 & 54 \\
\hline Total & 1,195 & 461 & 134 (29) & & & & \\
\hline
\end{tabular}

$P D$ power distance, $I N D$ individualism, $M A S$ masculinity, $U A$ uncertainty avoidance

a According to the World Directory of Medical Schools (WHO 2000, 2003)

b Dimensions and scores according to Hofstede (2001)

c Random stratified sample of 15

d No data were available for 1 or more universities in this country

e Except 1 university which did not offer pre-clinical training

${ }^{f}$ Excluded because only 5 curricula could be found

presented. In brief, we reasoned that implementation of an integrated curriculum requires a shift from departmental control over courses to curriculum control by multidisciplinary committees (Majoor and Kolle 1997). In schools in countries with strong Power distance professors may independently design the courses in their respective disciplines. By contrast, integration of the curriculum requires discussions with staff from different departments in interdisciplinary settings. Strong Power distance may impede heads of department to effectively participate in such negotiations. Curriculum change in a school in a country with strong Uncertainty avoidance may be difficult due to adherence of staff to existing national laws and university rules. "Fear of the unknown" may hamper curriculum innovation in those countries. Moreover, in some studies a significant correlation has been observed between the cultural dimensions Power distance and Uncertainty avoidance (Jippes and Majoor 2008; Hofstede 1991).

With respect to Individualism it has been demonstrated that managers in individualistic societies prefer undertaking innovations outside organizational norms, rules and procedures ("renegade championing"; Shane and Venkataraman 1996). This may explain the correlation between a high score on the Individualism index and a high percentage of schools with integrated curricula. Conversely, in a society with strong emphasis on Collectivism, harmony and mutual respect are very important. To change from a departmentally controlled curriculum towards an integrated curriculum negotiations among colleagues from different departments are necessary, which could elicit conflict and therefore may rather be avoided. 

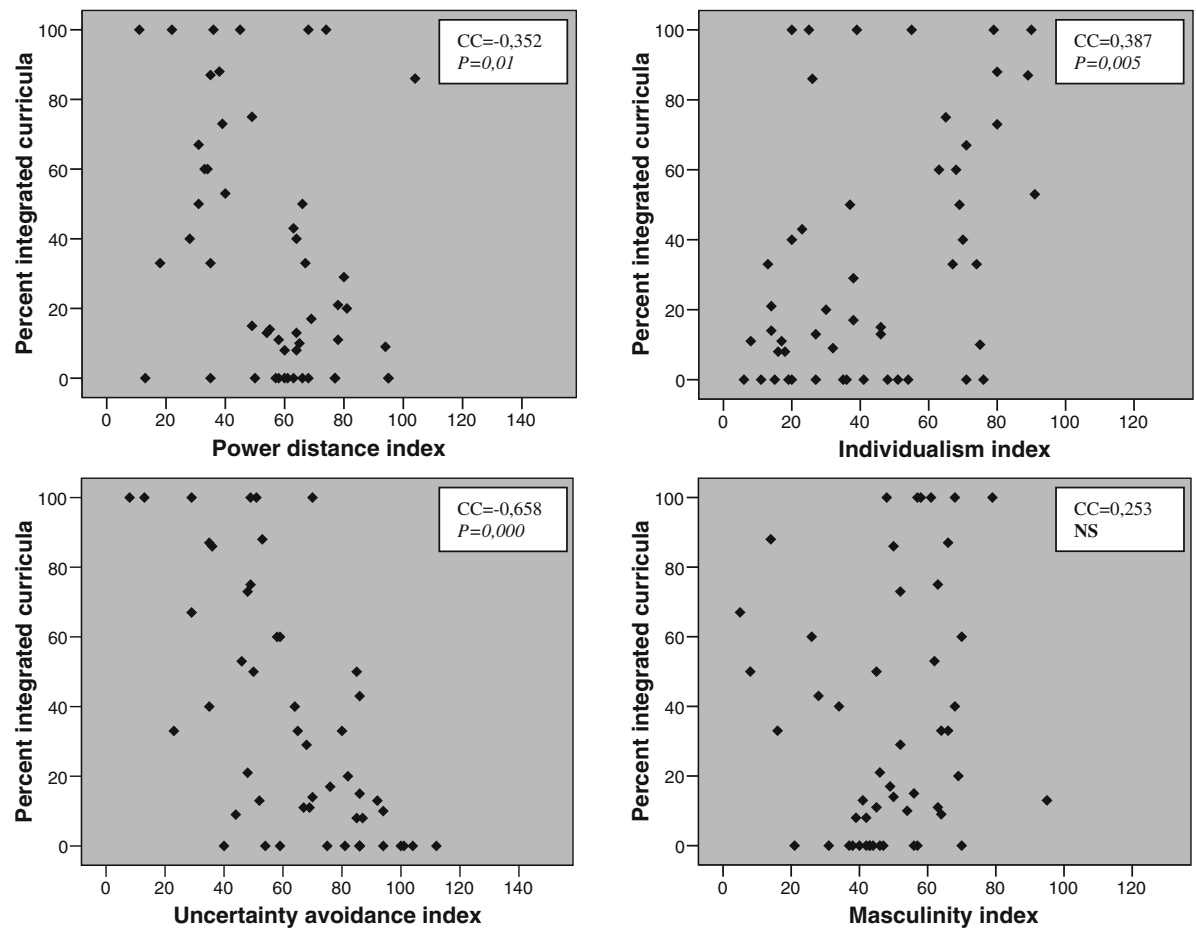

Fig. 1 Scatterplots of scores of 49 countries and 3 clusters of countries on indexes for each of 4 dimensions of culture (Hofstede 2001) and percent integrated medical curricula. CC correlation coefficient, NS not significant

Another possible explanation for the correlation between Collectivism and low percentage of integrated curricula may derive from the relation between the Individualism/ Collectivism dimension and gross domestic product (GDP). Strong Collectivism in a society has been shown to correlate with a low national GDP (Hofstede 2001). Obviously innovation of medical curricula (including transformation from non-integrated to integrated curricula) may be obstructed by lack of financial resources. For the countries examined in this study a low percentage of integrated curricula correlated with a low GDP (CC $=0.491, P=0.000)$ (two-tailed).

No correlation was found between the percentage of integrated curricula in a country and its score on the Masculinity index. Departing from the theoretical readiness of students to accept PBL, countries scoring low on Masculinity (and low on Uncertainty avoidance) were reasoned as more likely to adopt integrated curricula than countries scoring high on Masculinity (and high on Uncertainty avoidance; Stevens 2009).

However, several limitations of this study must be taken into account when estimating the reliability and validity of the outcomes. First, the definition of culture chosen may have negatively affected the validity of this study. Criticism on Hofstede's dimensions of culture includes doubts about the validity of his concept of 'national culture'. For instance, Baskerville (2003) noted that one nation may harbor several cultures, as demonstrated for instance in the Middle East where-according to the Encyclopedia of World Cultures-14 nations harbor 35 different cultures (O' Leary and Levinson 1991). Although analytical descriptions of culture different from Hofstede's are available, none of these assigned 
'quantitative' scores on 'cultural dimensions' to individual countries or regions (see for instance Schwartz and Bilsky (1987); Smith and Charles (2004); Trompenaars and Woolliams (2005)). Hence these descriptions of culture are not suited for a study as presented here.

Second, the inclusion criteria applied to define the world-wide sample of medical schools may have affected the reliability of the results. The World Directory of Medical Schools of 2000 was used to identify medical schools in Europe (WHO 2000). To list all schools beyond Europe the 2003 update of WDMS was used because 29 non-European schools were added compared to the 2000 edition (WHO 2003). The 2003 WDMS was used rather than a more recent update to ascertain that curricula had been in place for at least 5 years.

Third, overall from $9 \%$ of the schools in the sample no information could be obtained. There may be a bias in those non-responsive schools in terms of these being more conservative (e.g., because they do not feature a website) and having non-integrated curricula.

Fourth, another restriction with respect to the validity of the outcomes pertains to the discrimination of integrated and non-integrated curricula. Although the criterion of presence of two out of three basic sciences courses (i.e., Anatomy, Biochemistry and Physiology) is unambiguous, new names for "old" courses incidentally forced us to judge whether for instance 'functional morphology' was similar to anatomy and 'molecular chemistry' to biochemistry. In some medical curricula of schools in Latin America we found 'morphophysiology' courses occupying a prominent part of the program for the first 2 years including content matter from the three basic sciences specified above. Colleagues in Latin America assured us that such 'morphophysiology' courses are taught in the context of organ systems, and therefore should be considered integrated. In Indonesia, Japan, South Korea, as well as in the U.S. we encountered one school with a curriculum which was not integrated in the first and/or second year but clearly integrated in subsequent years. Such curricula may be referred to as 'hybrid curricula' (Nandi et al. 2000; Jaffarey 2001). In accord with our criterion these curricula were scored as non-integrated. We verified that changing the classification of these four curricula to 'integrated' did not change the conclusions from this study.

Fifth, another dilemma faced with respect to discriminating integrated and non-integrated curricula regarded schools in the U.S. and Canada, which are usually preceded by bachelor programs. For two reasons we decided to base our curriculum assessment on the first 2 years of the medical schools and to ignore the pre-medical bachelor programs. First, because we intended to assess curricula of medical schools and pre-medical bachelor programs may be offered by different schools. Second, even in medical schools which pioneered with implementation of integrated PBL curricula-like McMaster University in Canada and the University of New Mexico in the U.S.-pre-medical bachelor programs were found to be non-integrated.

To various extent reports in the literature supported our classification of integrated and non-integrated curricula. For the U.S. $70 \%$ of the medical schools were mentioned to have PBL (and thus integrated) curricula (Kinkade 2005); we scored 53\% of the $10.6 \%$ of all U.S. schools in our sample as having integrated curricula. Reports on the individual curricula of Ziauddin Medical University in Pakistan (Huda and Brula 1999), University of Transkei in South Africa (Iputo 1999), University of Hong Kong (Nandi et al. 2000), National University of Singapore (Khoo et al. 2001), and Rosario University in Argentina (Carrera et al. 2003) confirmed our independent classification of their curricula as integrated. Three reports described isolated PBL courses offered by different medical schools in India (Vyas et al. 2008; Chandra et al. 1996; Ghosh and Pandya 2008). This finding is 
not incompatible with our conclusion drawn from the sample of $10.3 \%$ of all medical schools in India that all had non-integrated curricula. The same holds for the National Yang-Ming University in Taiwan whose curriculum was assessed as non-integrated whereas some courses were reported to be taught in PBL format (Yu et al. 2000). Furthermore, we classified the curriculum of the University of Malaya in Malaysia as nonintegrated although from that school an article was published on the process of implementing an integrated curriculum (Azila et al. 2001). Perhaps that school's curriculum changed after our assessment.

Although this study has some limitations it demonstrates that national culture is associated with the propensity of medical schools to adopt integrated curricula. If a medical school is situated in a country with high scores on the indexes for Power distance and/or Uncertainty avoidance and/or a low score on the index for Individualism and considers adoption of an integrated or PBL curriculum, that school should take into account the potential hindering effects of these national cultural factors. To mitigate cultural barriers to curriculum innovation, resources are available providing advice with respect to strategies for change of an organization, both in general (Kotter 2003; William 2003) and specifically for medical and health professions schools (Neufeld et al. 1995).

We intend to expand our studies in two directions. Firstly, we aim to investigate whether scores on indexes for the three cultural dimensions counteracting curriculum change act independently or synergistically. Secondly, we intend to explore why in some countries with cultural characteristics counteracting curriculum change surprisingly many schools succeeded to implement integrated curricula. Studying the curriculum change processes performed in these 'outliers' may reveal factors which possibly can help to overcome adverse cultural conditions.

Acknowledgments We are grateful for assistance from many colleagues abroad; many of them known to us through The Network: Towards Unity for Health. Bilingual colleagues and acquaintances helped with translations from languages unknown to us to English. We are indebted to Prof. Cees van der Vleuten PhD, Erik Driessen PhD and Janneke Frambach MA for advice and support, and to Arno Muijtjens PhD for expert statistical advice.

Open Access This article is distributed under the terms of the Creative Commons Attribution Noncommercial License which permits any noncommercial use, distribution, and reproduction in any medium, provided the original author(s) and source are credited.

\section{References}

Azila, N. M., Sim, S. M., \& Atiya, A. S. (2001). Encouraging learning how to fish: An uphill but worthwhile battle. Annals of the Academy of Medicine, Singapore, 30(4), 375-378.

Aziz, L. R., \& Cullen, M. S. (1994). United Kingdom. In A. W. Sajid, C. H. Mcquire, R. M. Veach, L. R. Aziz, \& L. K. Gunzburger (Eds.), International handbook of medical education. (p. 397). Westport, CT: Greenwood Press.

Baskerville, R. F. (2003). Hofstede never studied culture. Accounting, Organizations and Society, 18, 1-14.

Bland, C. J., Starnaman, S., Wersal, L., Moorehead-Rosenberg, L., Zonia, S., \& Henry, R. (2000). Curricular change in medical schools: How to succeed. Academic Medicine, 75(6), 575-594.

Carrera, L. I., Tellez, T. E., \& D’Ottavio, A. E. (2003). Implementing a problem-based learning curriculum in an Argentinean medical school: implications for developing countries. Academic Medicine, 78(8), 798-801.

Chandra, D., Sharma, S., Sethi, G., \& Dkhar, S. (1996). Pharmacotherapeutic education through problem based learning and its impact on cognitive and motivational attitude of Indian students. European Journal of Clinical Pharmacology, 51(1), 1-5. 
Charlesworth, Z. M. (2008). Learning styles across cultures: Suggestions for educators. Education Training, 50(2), 115-127.

Davis, W. K., \& White, C. B. (2002). Managing the curriculum and managing change. In G. R. Norman, C. P. M. van der Vleuten, \& D. I. Newble (Eds.), International handbook of research in medical education (pp. 917-945). Dordrecht: Kluwer.

Eldridge, K., \& Cranston, N. (2009). Managing transnational education: Does national culture really matter? Journal of Higher Education Policy and Management, 31(1), 67-79.

FAIMER, International Medical Education Directory IMED. (2008). Retrieved July 21, 2008, from www.imed.faimer.org.

Ghosh, S., \& Pandya, H. (2008). Implementation of integrated learning program in neurosciences during first year of traditional medical course: Perception of students and faculty. BMC Medical Education, $8(1), 44$.

Gwee, M. C. (2008). Globalization of problem-based learning (PBL): Cross cultural implications. Kaohsiung Journal of Medical Sciences, 24(3 suppl), S14-S22.

Harden, R. M., Sowden, S., \& Dunn, W. R. (1984). Educational strategies in curriculum development: The SPICES model. Medical Education, 18(4), 284-297.

Hofstede, G. (1980). Culture's consequences: International differences in work-related values. London: Sage Publications.

Hofstede, G. (1991). Cultures and organizations: Software of the mind. London: McGraw-Hill.

Hofstede, G. (2001). Culture's consequences. Comparing values, behaviors, institutions, and organizations across nations. New York: Sage Publications.

Huda, N., \& Brula, A. Q. (1999). An introductory course on study skills forming a bridge between traditional and problem based learning (PBL). Journal of the Pakistan Medical Association, 49(2), 27-30.

Iputo, J. E. (1999). Impact of the problem-based learning curriculum on the learning styles and strategies of medical students at the University of Transkei. South African Medical Journal, 89(5), 550-554.

Jaffarey, N. A. (2001). Problem based learning. Journal of the Pakistan Medical Association, 51(8), 266-267.

Jippes, M., \& Majoor, G. D. (2008). Influence of national culture on the adoption of integrated and problembased curricula in Europe. Medical Education, 42(3), 279-285.

Khoo, H. E., Chem, R. K., Gwee, M. C., \& Balasubramaniam, P. (2001). Introduction of problem-based learning in a traditional medical curriculum in Singapore: Students' and tutors' perspectives. Annals of the Academy of Medicine, Singapore, 30(4), 371-374.

Kinkade, S. M. D. M. (2005). A snapshot of the status of problem-based learning in U.S. medical schools, 2003-04. Academic Medicine, 80(3), 300-301.

Kotter, J. P. (2003). Leading change. Boston: Harvard Business Publishing.

Majoor, G. D., \& Kolle, L. F. J. Th. M. (1997). Faculty planning and control in problem-based learning. Education for Health, 10(2), 189-198.

Nandi, P. L., Chan, J. N., Chan, C. P., Chan, P., \& Chan, L. P. (2000). Undergraduate medical education: Comparison of problem-based learning and conventional teaching. Hong Kong Medical Journal, 6(3), 301-306.

Neufeld, V., Khanna, S., Bramble, L., \& Simpson, J. (1995). Leadership for change in the education of health professionals. Maastricht: Network Publications.

O’Leary, T. J., \& Levinson, D. (1991). Encyclopedia of world cultures. Boston, MA: G.K. Hall \& Company.

Papa, F. J., \& Harasym, P. H. (1999). Medical curriculum reform in North America, 1765 to the present: A cognitive science perspective. Academic Medicine, 74(2), 154-164.

Schwartz, S. H., \& Bilsky, W. (1987). Toward a universal psychological structure of human values. Journal of Personality and Social Psychology, 53(3), 550-562.

Shane, S., \& Venkataraman, S. (1996). Renegade and rational championing strategies. Organization Studies, $17(5), 751$.

Smith, P. B., \& Charles, S. (2004). Values and culture. Encyclopedia of applied psychology. New York: Elsevier.

Stevens, F. C. J. (2009). Innovations in medical education. In C. Brosnan \& B. S. Turner (Eds.), Handbook of the sociology of medical education (pp. 278-295). New York, NY: Routledge.

Trompenaars, F. W. P., \& Woolliams, P. (2005). Business across cultures. West Sussex: Capstone publishing Ltd.

Vyas, R., Jacob, M., Faith, M., Isaac, B., Rabi, S., Sathishkumar, S., et al. (2008). An effective integrated learning programme in the first year of the medical course. National Medical Journal of India, 21(1), 21-26.

William, B. (2003). Managing transitions: Making the most of change. New York, NY: Basic books.

World Health Organization. (2000). World directory of medical schools. Geneva: WHO. 
World Health Organization. (2003). World directory of medical schools: Base year 2000. Updates through 30 June 2003. Retrieved July 21, 2008, from http://www.who.int/hrh/documents/en/wdms_update.pdf. Yu, H. Y., Wu, Z. A., Su, M. S., et al. (2000). Problem-based, small-group tutorial learning in clinical neurology for second-year medical students. Zhonghиa Yi Xие Za Zhi (Taipei), 63(8), 598-604. 